\title{
Does simulation suffice? Teaching procedural skills in undergraduate medical students- observational quasi-experimental study.
}

Katarzyna Naylor ( $\square$ Katarzyna.Naylor@hotmail.com )

Uniwersytet Medyczny w Lublinie https://orcid.org/0000-0002-1307-5015

Kamil Torres

Uniwersytet Medyczny w Lublinie

\section{Research article}

Keywords: low fidelity simulation, original instructional videos, Peyton's Four Step Approach, undergraduate medical education, basic clinical skills

Posted Date: December 11th, 2019

DOl: https://doi.org/10.21203/rs.2.18685/v1

License: (a) (1) This work is licensed under a Creative Commons Attribution 4.0 International License. Read Full License 


\section{Abstract}

Background. Medical simulation as a teaching method is concerned with close mirroring of the real clinical conditions, it is designed to develop skills from the clinical environment, under the guidance of experienced instructors, it allows standardization and repeatability of the skills taught. As a result, students acquire skills and competences, become acquainted with the medical equipment needed to perform a given procedure without endangering patients. The presented research attempts to evaluate the application of medical simulation techniques in the teaching of basic clinical skills using original instructional videos and the Peyton approach. Also, an attempt was made to assess how the applied interventions affect the assessment regarding the usefulness of the course by the students of medicine in comparison with the results of practical assessment in the form of OSCE.

Materials. The research was conducted in the period from May 2015 to June 2017, among 750 students of the medical faculty of the Medical University in Lublin. The study used a self-reported questionnaire and documentation analysis with the results of practical assessment. The obtained results were statistically analyzed.

Results. The overall students scored the BCS course high (good and very good). The highest values were assigned to Stage III of the research. The introduction of simulation techniques along with the original instructional videos and the Peyton approach positively reflected in the results obtained in the final assessment, OSCE, especially in case of invasive procedures: peripheral vein cannulation and urinary bladder catheterization.

Conclusions. Consequently, obtained results allowed concluding that the use of medical simulation techniques in the teaching of basic clinical skills using modern methodologies and teaching interventions: original instructional videos and the Peyton approach affected the positive assessment of the usefulness of the simulation course by students, as well as improve and support the process of acquiring basic skills clinical in the early years of medical training.

\section{Background}

Modern technology provides educators with the opportunity to enhance the teaching-learning process (1). Additionally, convenience is augmented by the ubiquity of technology in students' lives (2). In the process of ensuring patient safety, education, and training of healthcare professionals at all levels of education remain a crucial issue. The teaching methods used remain a very important element of the training process, both in terms of acquired skills, knowledge and acquired competencies (3) Continuous development and introduction of new didactic methods (e.g., medical simulation, virtual patients) to the training of medical personnel should improve the training environment and the effectiveness of the education process. It seems that medical simulation can help participants better understand and practice skills that will later be used to save patients' lives and improve their care $(4,5)$. 
On the other hand, rapid technological development and the introduction of advanced educational devices do not always improve the quality of education (6). Repeatedly, expensive technology without relying on its adaptation curricula does not meet the expectations of either educators nor learners themselves. Technology becomes only sophisticated toys in the form of advanced simulators (7-9).

Published research confirms that simple trainers used as teaching aids can help reproduce simple clinical situations that will better prepare medical staff to perform their duties at the patient's bedside. The use of training tools in the form of low fidelity simulations enables learning in a safe environment (10-12). However, their proper use during the educational process requires not only the right equipment but above all, the implementation of the appropriate skills $(3,13-15)$. Moreover, the complexity of the simulation technology used should be adapted to the current level of skills, knowledge, and experience of students to meet the educational requirements and achieve the objectives set (16). These tools should be used appropriately and gradually so as not to discourage or demotivate inexperienced students concerning this form of training in the future $(11,17,18)$.

The correct allocation and use of financial resources is a critical aspect raised increasingly in the environment of medical educators. This issue is particularly important when introducing expensive devices during simulation, especially the so-called high fidelity equipment. The financial aspect is especially important considering that the cost of an interactive patient simulator can be up to PLN $1,000,000$ and often requires a dedicated space and trained staff to support it, by ensuring its proper use during the teaching process.

Published studies prove the effectiveness of training with the use of simple task trainers in the process of teaching specific psychomotor skills $(19,20)$. In 2014, at the request of the Ministry of Health of Poland, a document entitled "Centers of Interdisciplinary Medical Education," based on which a standard for teaching based on medical simulation in Poland was developed. The presented document contained recommendations for creating technical and procedural skill rooms at Polish medical universities for faculties financed by the project support by the Ministry of Health as part of the POWER program (medical, dental, obstetrics and nursing)(21). Since the rules and teaching and assessment methods have not been specified in detail, as well as the correct selection of teaching and assessment methods in the context of procedural methods is an important research issue.

Dr. David Gaby described simulation as a technique, not a technology (22). Therefore, simulation requires extensive planning in the educational process, not only the introduction of the equipment itself.

In the presented work, we evaluate the use of medical simulation techniques in teaching basic clinical skills accompanied by original instructional videos and Peyton's four-step approach by assessing how the used interventions affected the students' subjective assessment compared to the results of practical assessment in the form of Objective Structured Clinical Examination.

\section{Methods}


This study was reviewed and approved by the local ethical committee (KE-0254/309/2015), which granted its acceptance of our study.

\subsection{Participants}

The sample population consisted of 806 first-, second- and fourth-year medical students enrolled in the Basic Clinical Skills course at the Medical University of Lublin (MUL), Poland.

The participation was voluntary. The research was implemented between June 2015 and June 2017. The respondents' group constituted of four subgroups:

I - a group from the first stage of research, II year medical students year 2014/2015,

II - a group from the second stage of research, II and IV years medical students, 2014/2015 and $2012 / 2013$

III - a group from the third stage of research, I year, medical students, 2016/2017,

IV - group from the third stage of research, Il year medical students, 2015/2016.

The study scheme is presented in Figure 1.

\subsection{Research instruments}

The research method was a diagnostic survey, and the tools - an original questionnaire and analysis of the practical final examination results of basic clinical skills.

Subjective feedback was collected using an original questionnaire with a five-point Likert scale (1-5) with the following answering format:

1. strongly disagree

2. rather disagree

3. no opinion

4. rather agree

5. strongly agree

Besides, the survey collected sociodemographic data.

The questionnaire in 2015 investigated participants' overall opinions on the course, as well as the usefulness of its content. It contained three sociodemographic questions: age, year of study, and place of residence.

The tool used in the second stage of the research with the original instructional videos included the questions mentioned above, as well as one concerning the use of instructional videos in teaching 
procedural skills, four sociodemographic questions were also added: age, year of study and place of residence, nationality.

Similarly, the third educational intervention in 2017, when the Peyton approach was introduced to the methodology of BSC laboratories, included questions on the opinion on the original instructional videos, the general course assessment, and its content. Three sociodemographic questions also were incorporated: age, year of study, and place of residence.

The research also analyzed documentation from practical exams OSCE carried out at the end of the course Basic Clinical Skills in 2015, 2016, and 2017. Data from the examination documentation were selected and used for this work.

The data included the content of checklists used during the OSCE:

$\nabla$ the total score of students from each of the five OSCE examination stations,

Q individual results of students from each of the five OSCE examination stations.

\subsection{Statistical analyses}

Data obtained from the examination documentation and questionnaires were collected in the Microsoft Excel database of the MS Office 2010 for Windows 10. The obtained results were subject to statistical analysis based on Statistica 13.1 (StatSoft Polska).

Descriptive and inferential statistical analyses were employed, depending on the variables tested. Significance tests were completed to examine the relationships between variables.

To study the differences between the two groups, the Student t-test was used for dependent samples as well as non-parametric tests for variable related tests (Wilcoxon test) and independent (Mann Whitney test). The $\chi^{2}$ test was used to assess the significant relationships between the analyzed qualitative variables. When the number of rows was not greater or equal to five in each cell of the table, the Yates correction for $2 \times 2$ tables was applied. Spearman's rank correlation was used to check the relationship between selected variables.

Logistic regression analysis investigated the impact of one variable on the other.

$P$-values less than 0.05 were considered as statistically significant.

The values of the analyzed qualitative data from the open responses were examined by the authors using a thematic analysis method to identify emerging themes. The study employed two coding strategies: a priori and a posteriori categorization of data. A priori coding focused on developing appropriate categories. A posteriori coding refers to developing categories based on the received data (23).

\subsection{Course Goal, Learning Objectives, Learning Method, and Activities}


Due to guidelines aimed at reducing the number of medical errors in invasive procedures, medical curricula are seeking ways to assist their students with mastering them through medical simulation (24).

The overall purpose of the course (in all three editions) was to help students acquire a deeper understanding and ability to perform most commonly performed basic procedural skills.

The Basic Clinical Skills (BCS) course lasted 15 teaching hours over the course of 5-weeks, and it was introduced as an innovative course for medical students of MUL, for the undergraduate medical program (a six-year curriculum. The lab sessions focused on practical procedural skills. Taught skills included bureau of vital signs (BVS) including heart valve auscultation, heart rate check (HR), peripheral vein cannulation (PVC), urinary bladder catheterization (UBC), digital rectal examination (DRE), later on, replaced by intramuscular injections (IM), and non-invasive blood examination, implemented on the task simulators ensuring the repetitiveness of the procedure, using online resources. BCS was implemented in the summer semester, just before students began nursing holiday clerkship. Assigned learning objectives were extracted from the Polish national regulation on teaching standards in the fields of medicine, dentistry, nursing, and obstetrics (25). Classes were conducted in groups of five by an interprofessional and interdisciplinary team of academic teachers with a minimum of 2-semester experience. Each year, the course coordinator organized a 3-hour training course to prepare for conducting laboratories to ensure teaching standardization. In the next stage, the instructors were trained by the technical team to use the appropriate task trainers.

\section{BSC 2015}

The first educational interventions in the form of teaching using medical simulation techniques were introduced for second-year medical students, the 2013-2019 study program (Figure 2).

\section{BCS 2016}

Subsequent educational intervention introduced into the structure of the BCS course based on medical simulation techniques was the use of original instructional videos presenting the taught procedures, which replaced the 30-minute theoretical part of the class. The purpose of this educational intervention was to increase the time allocated to practice without modifying their duration or financial costs. They were introduced for second-year (2014-2020) and fourth-year (2012-2018) medical students in the academic year 2016/2017 (Figure 3).

\section{BSC 2017}

The next educational intervention modified the teaching methodology of the BCS course by introducing the Peyton's approach, i.e., four-step methods: demonstration, deconstruction, comprehension, practice (26) in an academic semetre 2017/2018 (Figure 4).

\subsection{Objective Structured Clinical Examination}


The Objective Structured Clinical Examination was implemented at the end of the course, to provide an objective assessment of the skills acquired as it was found to be a reliable tool in assessing technical skills (27).

A division into five OSCE stations was introduced: auscultation of the heart and pulse rate, non-invasive blood pressure measurement, peripheral vein cannulation, urinary bladder catheterization and per rectum examination in the first stage of the examination, and intramuscular injection in the second and third stage instead of DRE with an adequate checklist for each station. The stations are described in the OSCE blueprint (Appendix 1).

To build a reliable assessment tool covering a range of basic clinical skills that were considered crucial for nursing clerkship, the OSCE scope was assembled using the Delphi method. Constructing the binary checklists was implemented through a repetitive consultation process with a team of experienced lecturers from the Medical University of Lublin until an agreement was reached on the components of checklists that should be included in the individual OSCE stations. The list of potential components of skills checked during the OSCE exam has been checked and ranked in order of priority.

This multi-stage process was carried out by a panel of experienced academic teachers of medical faculties who reviewed and suggested corrections on the marking scheme and construction of individual OSCE exam stations.

This process was intended to ensure that the tasks were appropriate to the student syllabus and whether they rated/checked what we wanted to assess with proper accuracy (its reliability). The panel of experts also assessed the consistency of the checklists used $(28,29)$.

Each consecutive year, teachers leading the assessment, as well as educationalists, analysed used binary checklists and submitted requested changes or modifications to the OSCE coordinator.

\section{Results}

The study results were allocated in two groups: 1) results from student scores of the summative final examinations OSCE, 2) results from the analysis of the survey questionnaires including students' perspectives on the overall course assessment in all three stages of the research as well as the students' perspectives concerning the substantial value of BCS course.

\subsection{Participants}

Seven hundred fifty medical students of MUL returned filled opinion questionnaires (93\%). The four student populations did not differ significantly in the ratio of men to women. However, a statistically significant difference was noticed in terms of age. Details are presented in Table 1.

\subsection{Final OSCE Scores}


Results of the final examination in the form of Objective Structured Clinical Examination of a total of 750 medical students were analyzed. The study population consisted of four groups of participants: low fidelity simulation course $(n=254)$, instructional video course $(n=77)$, and the two groups from the last stage: $n=195$ and $n=224$.

When comparing the overall results of OSCE pass rate between groups from three stages of introduced educational interventions during the BCS course, an increase is noticeable from the Stage I (69\%) in Stage 3 to $78 \%$ (I year) and 93\% (II year). The result of the 2nd year (4th group) in the third stage of the study consists of two randomly selected stations passing by the course participants, and in the remaining three groups (I, II, III), all five OSCE stations made up the final result of the exam. Figure 5 details the percentage of passing rates.

Even more when comparing the overall OSCE passing rate between individual research cohorts, research $p$-value $=0$ suggested a relationship between OSCE results, and the particular group of student depending $\mathrm{g}$ on the introduced intervention. The high correlation of these variables is also demonstrated by the high correlation coefficient $\mathrm{V}=0.25$.

When comparing the overall results of individual OSCE stations between the groups from Stage I (2nd year) and Stage 3 (1st year), both with each participant passing five stations during OSCE, statistically significant differences were noted. They were visible between the results obtained in the two most invasive procedures: peripheral vein cannulation $(p=0.001)$ and bladder catheterization $(p=0.000)$. Details are presented in Table 2.

\subsection{Subjective opinions of the participating medical students}

When analyzing results of the students' assessment concerning the BCS course (1- 5 on Likert scale) between the groups from the three stages of the research, a persistent high percentage of positive evaluations expressed by medical students at all stages of the study is visible. In all four cohorts, at least $90 \%$ of respondents rated the course good or very good ( 4 or 5 on the Likert scale). There is a slight increase visible from $96 \%$ in Stage I to $98 \%$ in both groups in Stage III of the research (Figure 6).

Additionally, we investigated the relationship between variables the overall subjective assessment of the BCS course and its substantive value scored by all the study respondents. In the case of the first edition of the course (Stage I, solely low fidelity simulation), the correlation was characterized by an average level as it was in the range of $0.3<=r<0.5$, nevertheless it was still statistically significant $(p<0.05)$. Similar strength of correlation was noted in Stage III, both groups, average but statistically significant. However, in the second edition of BCS course (Stage II with original instructional video) was high, in the range of $0.5<=R<0.7$ and was statistically significant $(p<0.05)$. Details are presented in Table 3 .

Linear regression examined the relationship between BCS subjective assessment and the overall results of the OSCE. No linear relationship was detected with regards to these two variables in any of the groups studied. Details are presented in Table 4. 
As a result of our investigation, the model of care concerning simulation teaching in medical education has been formulated. The model adhered to the theory of constructive alignment and starts with formulating appropriate learning objectives by the teachers based on their knowledge and experience. When the content of the course is known, a process of identifying appropriate teaching methods is implemented. The next step is concerned with designing suitable assessment, adhering to the learning objectives and teaching methods. In accordance with the theory of constructive alignment: the assessment was to support learning, and to reflect the implemented teaching methodology (63). Afterward, those elements are opinionated by the teachers and students to introduce necessary adjustments and modifications to increase the quality of learning process when it is next delivered. The process is presented on Figure 7.

\section{Discussion}

The presented research included a cohort of medical students from five different years participating in Basic Clinical Skills, enriched with further educational interventions. The essence of the study was not only to check the usefulness of the technology itself but to find an appropriate teaching methodology suited to the classes taught using low fidelity simulation (30). Participants achieved significantly better results through implementing all three educational interventions (low fidelity simulation, original instructional videos, and Peyton's Four-Step approach) during OSCE. Additionally, the comparison between the results in individual OSCE stations in Stage I and Stage III confirmed a statistically significant difference in case the most invasive procedures: peripheral vein cannulation and urinary bladder catheterization.

The changing landscape of higher education paves the way for methodological diversity in teaching, especially in connection with the increasing popularity of a model called flipped classroom. We adapted this model for the BCS course: students prepared theoretically to the class beforehand; they had original instructional video available prior to labs (II and III Stage). They familiarized themselves with them at the beginning of the laboratories, followed by their active participation (31). There is confirmed usefulness of the flipped classroom model in teaching procedural skills in recent research (32-34). Meta-analysis performed by Hew et al. gathered up-to-date evidence advocating for the flipped classroom approach as an educational model with a significant improvement in medical student learning (35). Wu et al. outlined a model hands-on where flipped classrooms assisted students in learning suturing skills (33).Similarly, Chiu et al. concluded as a result of their research; a simulation-based flipped classroom approach is one to advance laparoscopic intracorporeal knot-tying skill acquisition in medical students (34).

Another concept that has emerged over the past few years and relates to the methodological framework employed in our BCS course is blended learning. This approach relates to the combination of multimedia resources with face-to-face teaching (36). Blended learning postulates a link between video-based teaching and other methodological methods and means, using both online and face-to-face communication to provide participants with beneficial learning experiences and relevant outcomes as a result of these classes (37). Introduced BCS course was designed to combine the use of medical 
simulation techniques, exercises in small groups, video demonstrations, and Peyton's four-step approach as well as online resources in its final form. Blended learning was an underlying framework in that process.

Coyne et al. investigation recommended a combination of blended learning model integrating videoassisted online resources as a valuable tool to teach clinical skills to students of various health professions. Authors recommended it not only as a knowledge increasing model but due to its flexibility, which appealed to students (38). Our participants confirmed the appeal of such format, scoring high BCS on its overall assessment. Additionally, an increased in OSCE passing rate supported that model of teaching procedural skills. Saji et al., similarly to our research, combined both formats: blended learning and the flipped classroom. Obtained results pointed to blended learning, as achieving high student satisfaction. Whereas, flipped classrooms enabled active student-centered learning, enhancing information retention (39). Our results corroborated the positive opinions of participants in such a course.

Instructional videos themselves are placed within the cognitive theory of multimedia learning framework, documented as influential in terms of raising student motivation and improving their learning outcomes. This theory is based on three principles: 1) the existence of two different channels for processing visual and verbal stimuli; 2) each channel is characterized by limited capacity and a limited amount of information to be processed at once; 3) active processing is essential for learning to take place. These three stages concerned with choosing, organizing, and integrating information between those channels function as follows: students select the appropriate sounds, words, and images to be processed; afterward, they systematize them into a "mental model," i.e., they learn. Later, learners integrate it with their previous knowledge. So learning occurs through appropriate involvement in these three processes. For learning to happen, we must not only store knowledge in our long-term memory but be able to retrieve and employ it $(31,40)$. Mayer proved that the cognitive theory of multimedia learning resulted in the best results in students with low knowledge (41). Hence, novice undergraduate medical students from our research seem to be an ideal target group; and they confirmed that fact by assessing the course with original instructional videos positively ( $\mathrm{Me}=4$ and 5$)$.

BCS course was also an opportunity to practice invasive skills in a safe environment, ensuring repeatability and learning from your mistakes. Participants expressed their satisfaction with its format, assessing the positively overall idea of the course, as well as its substantive value. Even more, our results showed a significant positive correlation in the case of these two characteristics of BCS in all stages of the research. Pringle et al. confirmed the standardization of procedures taught during the course using low fidelity simulations in their study of a trauma course for medical students (42). The BCS course was also aimed at ensuring the transparency of procedures before their implementation in clinical settings, which is an essential goal of simulation teaching, and this has been confirmed by a high OSCE pass rate recorded amongst the participants. Kneebone et al. confirmed the effective transfer of skills taught in a simulation environment to clinical conditions (43). Similar examples of improved skills in medical students through simulation directly related to patient care practices include emergency procedural exercises in Draycott et al. obstetrics and Crofts et al. in situ training $(44,45)$. Walsh et al. proven that 
simulation classes supported by instructional videos prepared participants for the clinical environment, suggesting higher efficiency in the transfer of skills (46).

The implemented teaching with the use of medical simulation techniques was introduced under the recommendations for clinical skills curricula for medical students of the Association of American Medical Schools. These recommendations identify simulation as the direct predecessor of clinical teaching (47). BCS course preceded nursing practices, during which students had the opportunity to prepare for the clinical environment in conditions similar to them. Through immersion in a simulated clinical environment during students' performance of the taught procedures, participants practiced in conditions corresponding to the real ones. Without causing harm and pain, medical students could implement basic clinical procedures, step by step, acquaint themselves with the necessary equipment, and the correct method of operating this equipment (48). In the studies of other authors, the importance of these issues has been growing with decreasing acceptance of making mistakes while performing these procedures on patients $(49,50)$.

Similarly, introducing Peyton four-step approach adheres to the AAMC Recommendations on teaching procedural skills. This document emphasizes the

patient's centered approach associated with practicing the entire procedure, step by step, just like with a real patient in a clinical setting. What is more, the experience is also student-centered, as each participant practices the procedure as many times as required by mastering it in an interactive environment (47).

When analyzing obtained data, an increase in overall results of OSCE the Stage III is visible, compared to Stage I and Stage II. However, there is noticeable a significant increase in pass rates in invasive procedures: peripheral vein cannulation and urinary bladder catheterization. That effect was achieved in the group taught in our study with all three interventions (low fidelity simulation, original instructional videos, and Peyton's four-step approach. Their improvement was noticeable when performing urinary catheterization and peripheral vein cannulation, the two-invasive procedure prone to errors when performed in a clinical environment, as well as causing amplified discomfort when inappropriately implemented $(51,52)$. Body of evidence outlined a prove concerning the usefulness of instructional videos in teaching urinary bladder catheterization procedure ((46) and Peyton's four-step approach in teaching peripheral vein cannulation (26). Nevertheless, a combination of both is a novelty in those procedures.

What is essential, employed educational interventions did not require any modification in the time devoted to laboratories or additional financial input (53). All groups had five sessions, 135 minutes each. There was no increase in student to educator ratio. The learning experience was effective as it was high in active practice, but not generating additional cost. That cost-effectiveness is a crucial factor in determining modification in medical curricula (54). That cost-effectiveness also sought to correspond to results in reducing the number of medical errors $(55,56)$.

Three implemented educational intervention possess some limitations, reported in the literature. The absence of changing conditions can be used as a counterargument to the benefits of low fidelity

Page $11 / 25$ 
simulations $(6,11,57)$. Whereas, in the case of instructional videos, there is research that found no correlation between the introduction of the instructional videos themselves during the courses and improving the results during the exam (58-60). Similarly, the implementation of the Peyton four-step approach showed a lack of improvement in taught skills $(61,62)$. However, this research included individual educational intervention, not supported by other teaching methods.

\section{Limitations}

The following limitations apply to our research. Firstly: we implemented the study with a cohort of medical students from one institution. Their particular level of training and education might have affected the results in a different way than an assessment of medical professionals would have had. There was no randomization of the procedure, as they were implemented in a course embedded in the curriculum. Also, course assessment and its substantial value were self-rated; this may have played a role.

\section{Conclusions}

The introduction of simulation techniques along with the original instructional videos and the Peyton four-step approach was positively reflected in the results obtained during the final assessment, OSCE, especially in case of invasive procedures: peripheral vein cannulation and catheterization of the urinary bladder. Amongst researched participants, the link was revealed between the positive evaluation of the course and its substantive content at all stages of the study. Consequently, obtained results allow concluding that the use of medical simulation techniques in the teaching of basic clinical skills using modern methodologies and teaching interventions: original instructional videos and the Peyton four-step approach affected the positive assessment of the usefulness of the simulation course by students, as well as improve and support the process of acquiring basic skills clinical in the early years of medical training. Therefore, complex methodological teaching approaches affect positively simulation based learning.

\section{Declarations}

Ethics approval and consent to participate

The Ethical Committee of Medical University of Lublin approved of the study (permission no KE0254/309/2015). All procedures performed in studies involving human participants were in accordance with the 1964 Helsinki declaration and its later amendments. All participants gave a written consent to participate in the research.

Consent for publication

The authors consent to the publishing of the article in BMC Education.

Availability of data and material 
The study datasets are available from the corresponding author on reasonable request due to the data protection.

Competing interests:

The authors report no financial and non-financial competing interests. The authors alone are responsible for the content and writing of the paper.

Authors' contributions

$\mathrm{KT}$ and $\mathrm{KN}$ has made substantial contributions to conception and design of the article;

$\mathrm{KN}$ was involved in acquisition of data;

$\mathrm{KN}$ was responsible for data analysis and interpretation of data

$\mathrm{KN}$ and $\mathrm{KT}$ have been involved in drafting the manuscript

$\mathrm{KT}$ and $\mathrm{KN}$ was involved in revising the manuscript critically for important intellectual content and has given final approval of the version to be published.

Funding

The facilities and the simulation equipment used during all stages of BCS course were financed by the European Union Operational Programme Knowledge Education Development 2016 - 2021: Priority V Support for the health sector 5.3 High quality of teaching in medical education.

MedIQ- simulation in education - the developmental program of Medical University of Lublin.

However, it did not play any role in in the design of the study; collection, analysis, or interpretation of data; and in writing the manuscript.

Acknowledgments

We would like to express our gratitude to all study participants as well as the teachers leading the Basic Clinical Skills course.

\section{Abbreviations}

BCS- basic clinical skills

HR- heart rate

MUL- Medical University of Lublin 
NBP- non-invasive blood pressure measurement

OSCE- Objective Structured Clinical Examination

PVC- peripheral vein cannulation

UBC- urinary bladder catheterization

\section{References}

1. Torres A, Staśkiewicz GJ, Lisiecka J, Pietrzyk Ł, Czekajlo M, Arancibia CU, et al. Bridging the gap between basic and clinical sciences: A description of a radiological anatomy course. Anat Sci Educ. 2016 May 6;9(3):295-303.

2. Martín-Blas T, Serrano-Fernández A. The role of new technologies in the learning process: Moodle as a teaching tool in Physics. Comput Educ. 2009 Jan 1;52(1):35-44.

3. Miller GE. The assessment of clinical skills/competence/performance. Acad Med. 1990 Sep;65(9 Suppl):S63-7.

4. Beyer-Berjot L, Aggarwal R. Toward technology-supported surgical training: the potential of virtual simulators in laparoscopic surgery. Scand J Surg. 2013 Dec 20;102(4):221-6.

5. Michael M, Abboudi H, Ker J, Shamim Khan M, Dasgupta P, Ahmed K. Performance of technologydriven simulators for medical students-a systematic review. J Surg Res. 2014 Dec;192(2):531-43.

6. Massoth C, Röder H, Ohlenburg H, Hessler M, Zarbock A, Pöpping DM, et al. High-fidelity is not superior to low-fidelity simulation but leads to overconfidence in medical students. BMC Med Educ. 2019;19.

7. Motola I, Devine LA, Chung HS, Sullivan JE, Issenberg SB. Simulation in healthcare education: A best evidence practical guide. AMEE Guide No. 82. Med Teach. 2013 Oct 13;35(10):e1511-30.

8. Baker BG, Bhalla A, Doleman B, Yarnold E, Simons S, Lund JN, et al. Simulation fails to replicate stress in trainees performing a technical procedure in the clinical environment. Med Teach. $2017 \mathrm{Jan}$ 2;39(1):53-7.

9. Cook DA, Hamstra SJ, Brydges R, Zendejas B, Szostek JH, Wang AT, et al. Comparative effectiveness of instructional design features in simulation-based education: Systematic review and meta-analysis. Med Teach. 2013 Jan 3;35(1):e867-98.

10. Walker S, Thrasher AB. Use of Simulation to Develop Clinical Skills: Part 1, Low-Fidelity Simulators. Martin M, editor. Int J Athl Ther Train. 2013 Mar 1;18(2):20-3.

11. Munshi F, Lababidi $\mathrm{H}$, Alyousef $\mathrm{S}$. Low- versus high-fidelity simulations in teaching and assessing clinical skills. J Taibah Univ Med Sci. 2015 Mar 1;10(1):12-5.

12. Healey A, Sherbino J, Fan J, Mensour M, Upadhye S, Wasi P. A low-fidelity simulation curriculum addresses needs identified by faculty and improves the comfort level of senior internal medicine resident physicians with inhospital resuscitation*. Crit Care Med. 2010 Sep;38(9):1899-903. 
13. Chiniara G, Cole G, Brisbin K, Huffman D, Cragg B, Lamacchia M, et al. Simulation in healthcare: A taxonomy and a conceptual framework for instructional design and media selection. Med Teach. 2013 Aug 2;35(8):e1380-95.

14. Rivière $E$, Saucier $D$, Lafleur A, Lacasse M, Chiniara G. Twelve tips for efficient procedural simulation. Med Teach. 2018 Jul 3;40(7):743-51.

15. AAMC. Recommendations For Clinical Skills Curricula For Undergraduate Medical Education Recommendations for Preclerkship Clinical Skills Education for Undergraduate Medical Education Task Force on the Clinical Skills Education of Medical Students. 2008.

16. Beaubien JM, Baker DP. The use of simulation for training teamwork skills in health care: how low can you go? Qual Saf Health Care. 2004 Oct;13 Suppl 1(Suppl 1):i51-6.

17. Haji FA, Cheung JJH, Woods N, Regehr G, de Ribaupierre S, Dubrowski A. Thrive or overload? The effect of task complexity on novices' simulation-based learning. Med Educ. 2016 Sep;50(9):955-68.

18. Alinier G. A typology of educationally focused medical simulation tools. Med Teach. 2007 Jan 3;29(8):e243-50.

19. Lund F, Schultz J-H, Maatouk I, Krautter M, Möltner A, Werner A, et al. Effectiveness of IV Cannulation Skills Laboratory Training and Its Transfer into Clinical Practice: A Randomized, Controlled Trial. Phillips RS, editor. PLoS One. 2012 Mar 12;7(3):e32831.

20. Woelfel IA, Takabe K. Successful intravenous catheterization by medical students. J Surg Res. 2016 Aug;204(2):351-60.

21. 5.3 Wysoka jakość kształcenia na kierunkach medycznych - Ministerstwo Inwestycji i Rozwoju [Internet]. [cited 2019 Feb 7]. Available from: https://www.power.gov.pl/nabory/1-38/

22. Gaba DM. The future vision of simulation in health care. Qual Saf Heal Care. 2004 Oct 1;13(suppl_1):i2-10.

23. Sinkovics RR, Penz E, Ghauri PN. Enhancing the Trustworthiness of Qualitative Research in International Business. Manag Int Rev. 2008 Dec 5;48(6):689-714.

24. Sarfati L, Ranchon F, Vantard N, Schwiertz V, Larbre V, Parat S, et al. Human-simulation-based learning to prevent medication error: A systematic review. J Eval Clin Pract. 2019 Feb;25(1):11-20.

25. Department of Health. The Bill of Polish Health Ministry on education standards in case of medical students. [Rozporządzenie Ministra Nauki i Szkolnictwa Wyższego z dnia 9 maja 2012 r. w sprawie standardów kształcenia dla kierunków studiów: lekarskiego, lekarsko-dentystycznego, farmacji, pielęgniarstwa i położnictwa] [Internet]. Bill. 2012 [cited 2019 Jul 30]. p. 89. Available from: http://prawo.sejm.gov.pl/isap.nsf/DocDetails.xsp?id=WDU20120000631

26. Nikendei C, Huber J, Stiepak J, Huhn D, Lauter J, Herzog W, et al. Modification of Peyton's four-step approach for small group teaching - a descriptive study. BMC Med Educ. 2014 Dec 2;14(1):68.

27. Hodges B. OSCE! Variations on a theme by Harden. Med Educ. 2003 Dec;37(12):1134-40.

28. Stewart CM, Masood H, Pandian V, Laeeq K, Akst L, Francis HW, et al. Development and pilot testing of an objective structured clinical examination (OSCE) on hoarseness. Laryngoscope. 2010 
Nov;120(11):2177-82.

29. Van Der Vleuten CPM. The assessment of professional competence: Developments, research and practical implications. Adv Heal Sci Educ. 1996 Jan;1(1):41-67.

30. Nestel D, Groom J, Eikeland-Husebø S, O’Donnell JM. Simulation for Learning and Teaching Procedural Skills. Simul Healthc J Soc Simul Healthc. 2011 Aug;6:S10-3.

31. Carmichael M, Reid A-K, Karpicke JD, Bradley J V. Assessing the Impact of Educational Video on Student Engagement, Critical Thinking and Learning: The Current State of Play.

32. Katz L, Finch A, McKinnish T, Gilliland K, Tolleson-Rinehart S, Marks B. Teaching procedural skills to medical students: A pilot procedural skills lab. Educ Heal. 2017;30(1):79.

33. Wu J-C, Chi S-C, Wu C-C, Kang Y-N. Helps from flipped classroom in learning suturing skill: The medical students' perspective. PLoS One. 2018;13(10):e0204698.

34. Chiu H-Y, Kang Y-N, Wang W-L, Huang H-C, Wu C-C, Hsu W, et al. The Effectiveness of a SimulationBased Flipped Classroom in the Acquisition of Laparoscopic Suturing Skills in Medical Students-A Pilot Study. J Surg Educ. 2018 Mar;75(2):326-32.

35. HEW KF, LO CK. Flipped classroom improves student learning in health professions education: a meta-analysis. BMC Med Educ. 2018 Dec 15;18(1):38.

36. Margolis AR, Porter AL, Pitterle ME. Best Practices for Use of Blended Learning. Am J Pharm Educ. 2017 Apr;81(3):49.

37. Yousef Ahmed Mohamed Fahmy, Chatti Mohamed Amine, Schroeder Ulrik. Video-Based Learning: A Critical Analysis of The Research Published in 2003-2013 and Future Visions. In: The Sixth International Conference on Mobile, Hybrid, and On-line Learning. Nice: IARIA; 2014. p. 112-9.

38. Coyne E, Rands H, Frommolt V, Kain V, Plugge M, Mitchell M. Investigation of blended learning video resources to teach health students clinical skills: An integrative review. Nurse Educ Today. 2018 Apr;63:101-7.

39. Sajid MR, Laheji AF, Abothenain F, Salam Y, AlJayar D, Obeidat A. Can blended learning and the flipped classroom improve student learning and satisfaction in Saudi Arabia? Int J Med Educ. 2016 Sep 4;7:281-5.

40. Clark RC, Mayer RE. E-learning and the science of instruction: proven guidelines for consumers and designers of multimedia learning. $527 \mathrm{p}$.

41. Mayer RE. Multimedia learning: Are we asking the right questions? Educ Psychol. 1997 Jan;32(1):119.

42. Pringle K, Mackey JM, Modi P, Janeway H, Romero T, Meynard F, et al. "A short trauma course for physicians in a resource-limited setting: Is low-cost simulation effective?" Injury. 2015 Sep;46(9):1796-800.

43. Kneebone R, Kidd J, Nestel D, Asvall S, Paraskeva P, Darzi A. An innovative model for teaching and learning clinical procedures. Med Educ. 2002 Jul;36(7):628-34. 
44. Draycott TJ, Crofts JF, Ash JP, Wilson L V., Yard E, Sibanda T, et al. Improving Neonatal Outcome Through Practical Shoulder Dystocia Training. Obstet Gynecol. 2008 Jul;112(1):14-20.

45. Crofts JF, Bartlett C, Ellis D, Hunt LP, Fox R, Draycott TJ. Training for Shoulder Dystocia. Obstet Gynecol. 2006 Dec;108(6):1477-85.

46. Walsh CM, Rose DN, Dubrowski A, Ling SC, Grierson LEM, Backstein D, et al. Learning in the Simulated Setting: A Comparison of Expert-, Peer-, and Computer-Assisted Learning. Acad Med. 2011 Oct;86(10 Suppl):S12-6.

47. Aamc. Recommendations For Clinical Skills Curricula For Undergraduate Medical Education Recommendations for Preclerkship Clinical Skills Education for Undergraduate Medical Education Task Force on the Clinical Skills Education of Medical Students.

48. Zarajczyk M, Iwanowicz-Palus GJ, Bień A, Rzońca E, Korżyńska-Piętas M. Medical simulation in medical science education. Vol. 4, European Journal of Medical Technologies. 2016.

49. Okuda Y, Bryson EO, DeMaria S, Jacobson L, Quinones J, Shen B, et al. The Utility of Simulation in Medical Education: What Is the Evidence? Mt Sinai J Med A J Transl Pers Med. 2009 Aug 1;76(4):330-43.

50. To Err Is Human. Washington, D.C.: National Academies Press; 2000.

51. Miliani K, Taravella R, Thillard D, Chauvin V, Martin E, Edouard S, et al. Peripheral Venous CatheterRelated Adverse Events: Evaluation from a Multicentre Epidemiological Study in France (the CATHEVAL Project). PLoS One. 2017;12(1):e0168637.

52. Feneley RCL, Hopley IB, Wells PNT. Urinary catheters: history, current status, adverse events and research agenda. J Med Eng Technol. 2015;39(8):459-70.

53. Brown C, Ross S, Cleland J, Walsh K. Money makes the (medical assessment) world go round: The cost of components of a summative final year Objective Structured Clinical Examination (OSCE). Med Teach. 2015 Jul 3;37(7):653-9.

54. Chichester M, Hall NJ, Wyatt TL, Pomilla R. A Cost-Effective Approach to Simulation-Based Team Training in Obstetrics. Nurs Womens Health. 2014 Dec;18(6):500-7.

55. van de Ven J, Houterman S, Steinweg RA, Scherpbier AJ, Wijers W, Mol BWJ, et al. Reducing errors in health care: cost-effectiveness of multidisciplinary team training in obstetric emergencies (TOSTI study); a randomised controlled trial. BMC Pregnancy Childbirth. 2010 Dec 8;10(1):59.

56. Forster R, Ratcliffe A, Lewis M, Crossley A, Bastida JL, Dunlop WCN. Cost-utility analysis of an intervention designed to reduce the critical handling error of insufficient inspiratory effort. Eur $\mathrm{J}$ Heal Econ. 2018 Dec 12;19(9):1303-18.

57. Conlon LW, Rodgers DL, Shofer FS, Lipschik GY. Impact of Levels of Simulation Fidelity on Training of Interns in ACLS. Hosp Pract. 2014 Oct 13;42(4):135-41.

58. Saxena V, Natarajan P, O'Sullivan PS, Jain S. Effect of the use of instructional anatomy videos on student performance. Anat Sci Educ. 2008 Jul;1(4):159-65. 
59. Colley P, Mace JC, Schaberg MR, Smith TL, Tabaee A. Impact of educational intervention on the interrater agreement of nasal endoscopy interpretation. Laryngoscope. 2015 Oct;125(10):2259-65.

60. Mahmud W, Hyder O, Butt J, Aftab A. Dissection videos do not improve anatomy examination scores. Anat Sci Educ. 2011 Jan;4(1):16-21.

61. Jenko M, Frangez M, Manohin A. Four-stage teaching technique and chest compression performance of medical students compared to conventional technique. Croat Med J. 2012 Oct;53(5):486-95.

62. Orde S, Celenza A, Pinder M. A randomised trial comparing a 4-stage to 2-stage teaching technique for laryngeal mask insertion. Resuscitation. 2010 Dec;81(12):1687-91.

63. Biggs JB, Tang C. Teaching For Quality Learning At Universityle. Maidenhead: McGraw - Hill Education; 2011. 97 p.

\section{Tables}

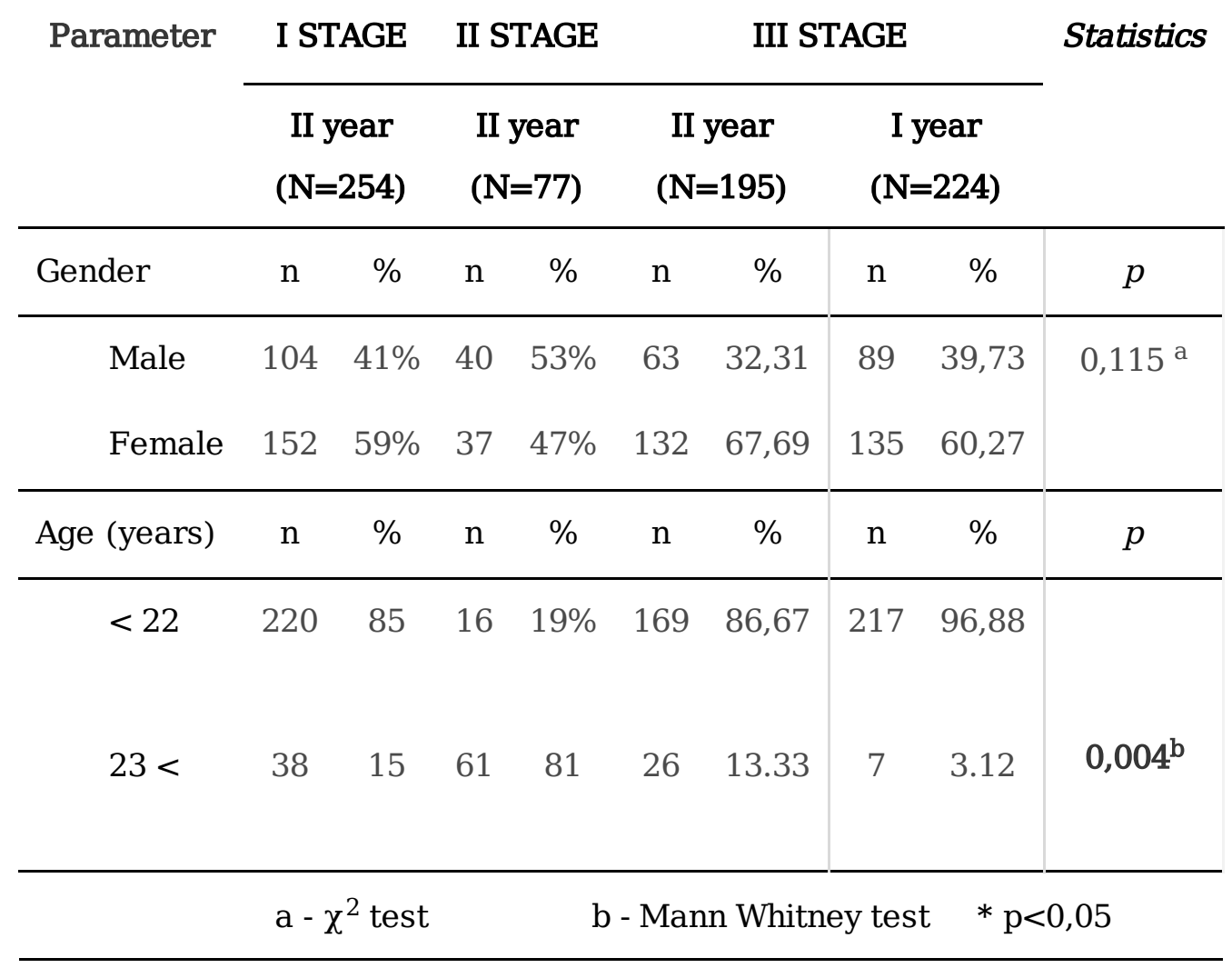

Table 1. Sociodemographic characteristics of the research group. 


\begin{tabular}{|c|c|c|c|c|c|c|c|c|c|c|}
\hline \multirow[b]{3}{*}{$\nabla$ OSCE stations } & \multicolumn{3}{|c|}{$\begin{array}{l}\text { Stage I } \\
\mathrm{n}=264\end{array}$} & \multicolumn{4}{|c|}{$\begin{array}{c}\text { Stage III } \\
n=224\end{array}$} & \multirow[b]{3}{*}{$x^{2}$} & \multirow[b]{3}{*}{ df } & \multirow[b]{3}{*}{ p* } \\
\hline & Pass & \multicolumn{2}{|c|}{ Fail } & \multicolumn{2}{|c|}{ Pass } & \multicolumn{2}{|c|}{ Fail } & & & \\
\hline & n $\quad \%$ & $\mathbf{n}$ & $\%$ & $\mathbf{n}$ & $\%$ & $\mathbf{n}$ & $\%$ & & & \\
\hline NBP & 25998,11 & 5 & 1,89 & 218 & 97,32 & 6 & 2,68 & 0,34 & 1 & 0,561 \\
\hline HR & 25696,97 & 8 & 3,03 & 213 & 95,09 & 11 & 4,91 & 1,15 & 1 & 0,285 \\
\hline $\begin{array}{l}\text { Auscultation of } \\
\text { heart valves }\end{array}$ & 25897,73 & 6 & 2,27 & 215 & 95,98 & 9 & 4,02 & 1,24 & 1 & 0,266 \\
\hline PVC & 24492,42 & 20 & 7,58 & 221 & 98,66 & 3 & 1,34 & 10,49 & 1 & 0,001 \\
\hline UBC & 20276,52 & 62 & 23,48 & 204 & 91,07 & 20 & 8,93 & 18,37 & 1 & 0,000 \\
\hline
\end{tabular}

Legend

NBP- non-invasive blood pressure measurement

HR- heart rate

PVC- peripheral vein cannulation

UBC- urinary bladder catheterization

Table 2.Comparison of individual stations results between the groups from the Stage I (low fidelity simulation) and Stage 3 (Peyton's four-step approach) of the research.

\begin{tabular}{|c|c|c|c|c|c|}
\hline \multirow[t]{2}{*}{ Variables } & \multicolumn{2}{|c|}{ Stages } & \multicolumn{3}{|c|}{ R Spearman correlation } \\
\hline & & & $\mathrm{n}$ & R Spearman & $\mathrm{p}$ \\
\hline \multirow{4}{*}{$\begin{array}{l}\text { Substantive content } \\
\text { vs. course assessment }\end{array}$} & Stage I & II year & 258 & 0,326 & $0,000 *$ \\
\hline & Stage II & II year & 77 & 0,637 & $0,000 *$ \\
\hline & Stage III & II year & 193 & 0,446 & 0,000 \\
\hline & & I year & 223 & 0,132 & 0,050 \\
\hline & $* 1$ & $<0,05$ & & & \\
\hline
\end{tabular}


Table 3. Subjective assessment of the course vs. subjective assessment of the substantive content of the course.

Variable

\begin{tabular}{cccccccccc} 
& \multicolumn{2}{c}{ I } & \multicolumn{2}{c}{ II } & \multicolumn{2}{c}{ III } & \multicolumn{2}{c}{ IV } \\
& \multicolumn{2}{c}{$\chi^{2}(1)=0,786$} & $\chi^{2}(1)=0,0001$ & \multicolumn{2}{c}{$\chi^{2}(1)=$} & \multicolumn{2}{c}{$\chi^{2}(1)=0,021$} \\
& $\mathrm{t}$ & $\mathrm{p}^{*}$ & $\mathrm{t}$ & $\mathrm{p} *$ & $\mathrm{t}$ & $\mathrm{p}^{*}$ & $\mathrm{t}$ & $\mathrm{p} *$ \\
\hline $\begin{array}{c}\text { Participants' assessment of } \\
\text { BCS course }\end{array}$ & -0.865 & 0.387 & -0.012 & 0.990 & 0.427 & 0.669 & -0.145 & 0.884 \\
\hline
\end{tabular}

${ }^{*} \mathrm{p}<0.05 ; \mathrm{t}$ - Student $\mathrm{t}$-test value testing the significance of parameters; $\mathrm{p}$ - significance level

$$
\chi^{2}-\text { logistic regression }
$$

Legend

I - Stage I group, II year of medical students 2015; II- Stage II group, II year, and IV year of m.s. 2016

III- Stage III group, I year of medical students 2017; IV- Stage III group, II year of medical students 2017

Table 4. Linear regression analysis for overall OSCE results and course evaluation.

\section{Figures}




\begin{tabular}{|c|c|c|c|}
\hline & $\underset{2015}{\operatorname{STAGE}} \rightarrow$ & $\underset{2016}{\text { II }} \rightarrow$ & $\underset{2017}{\operatorname{STAGE}} \rightarrow$ \\
\hline RESEARCH GROUP & II & II , IV & I rok, II rok \\
\hline $\begin{array}{c}806 \\
\text { students }\end{array}$ & $\begin{array}{c}299 \\
\text { students }\end{array}$ & $\begin{array}{c}88 \\
\text { students }\end{array}$ & $\begin{array}{l}224+195 \\
\text { students }\end{array}$ \\
\hline $\begin{array}{l}\text { EDUCATIONAL } \\
\text { INTERVENTIONS }\end{array}$ & Low fidelity simulation & Original instruc tional vid eos & Peyton's four step approach \\
\hline
\end{tabular}

\section{Figure 1}

Scheme of the research.

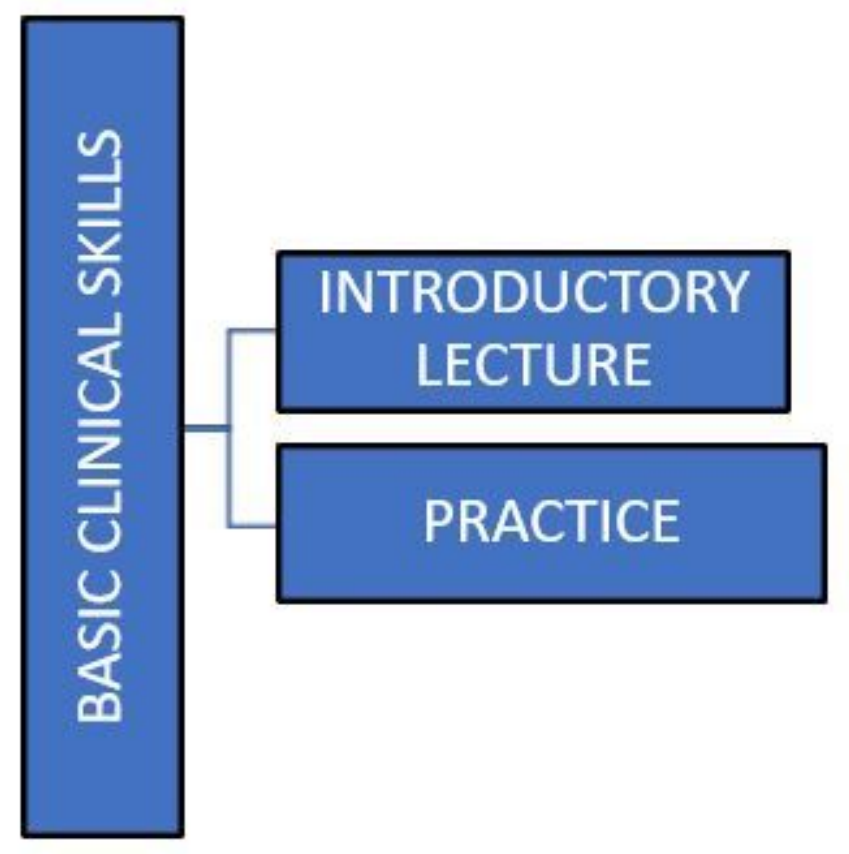

\section{Figure 2}

The structure of the Basic Clinical Skills class in 2015. 


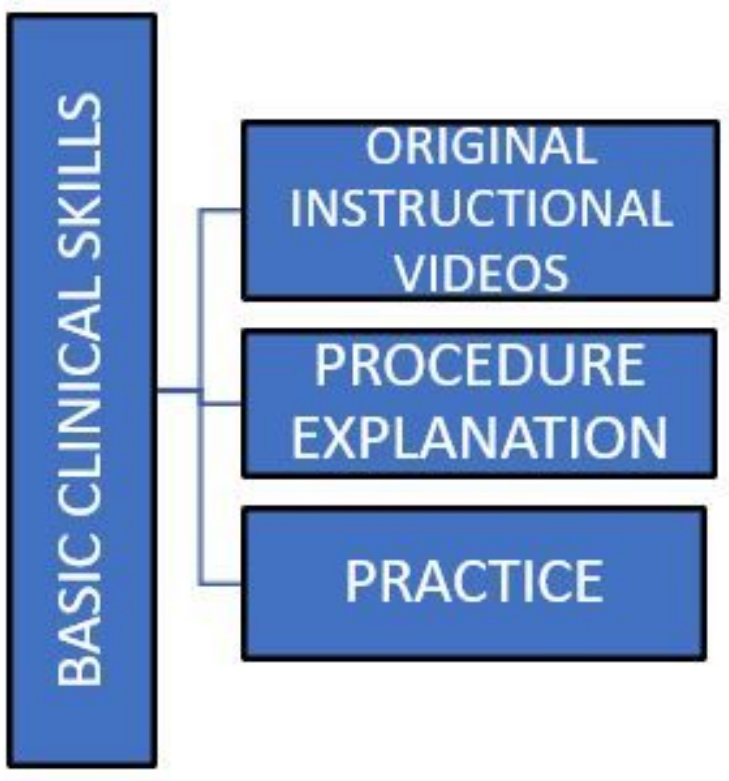

Figure 3

The structure of the Basic Clinical Skills class in 2016.

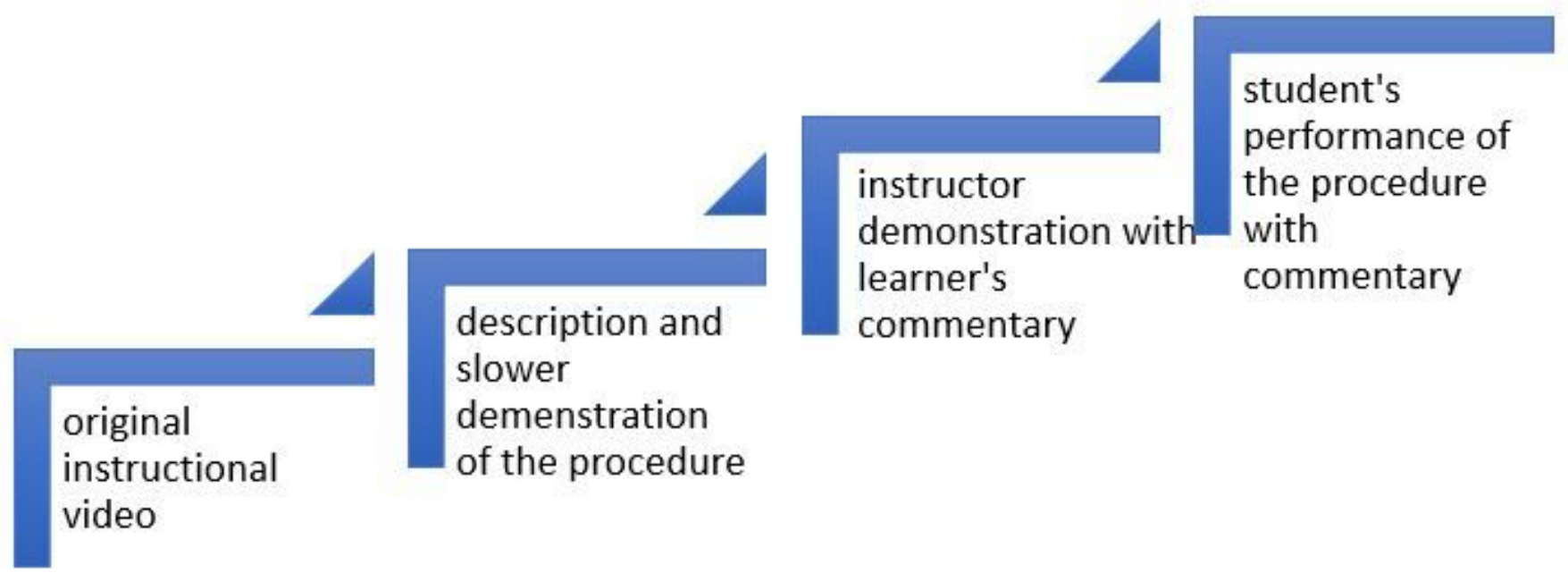

Figure 4

The structure of BSC supplemented with Peyton's approach in 2017. 


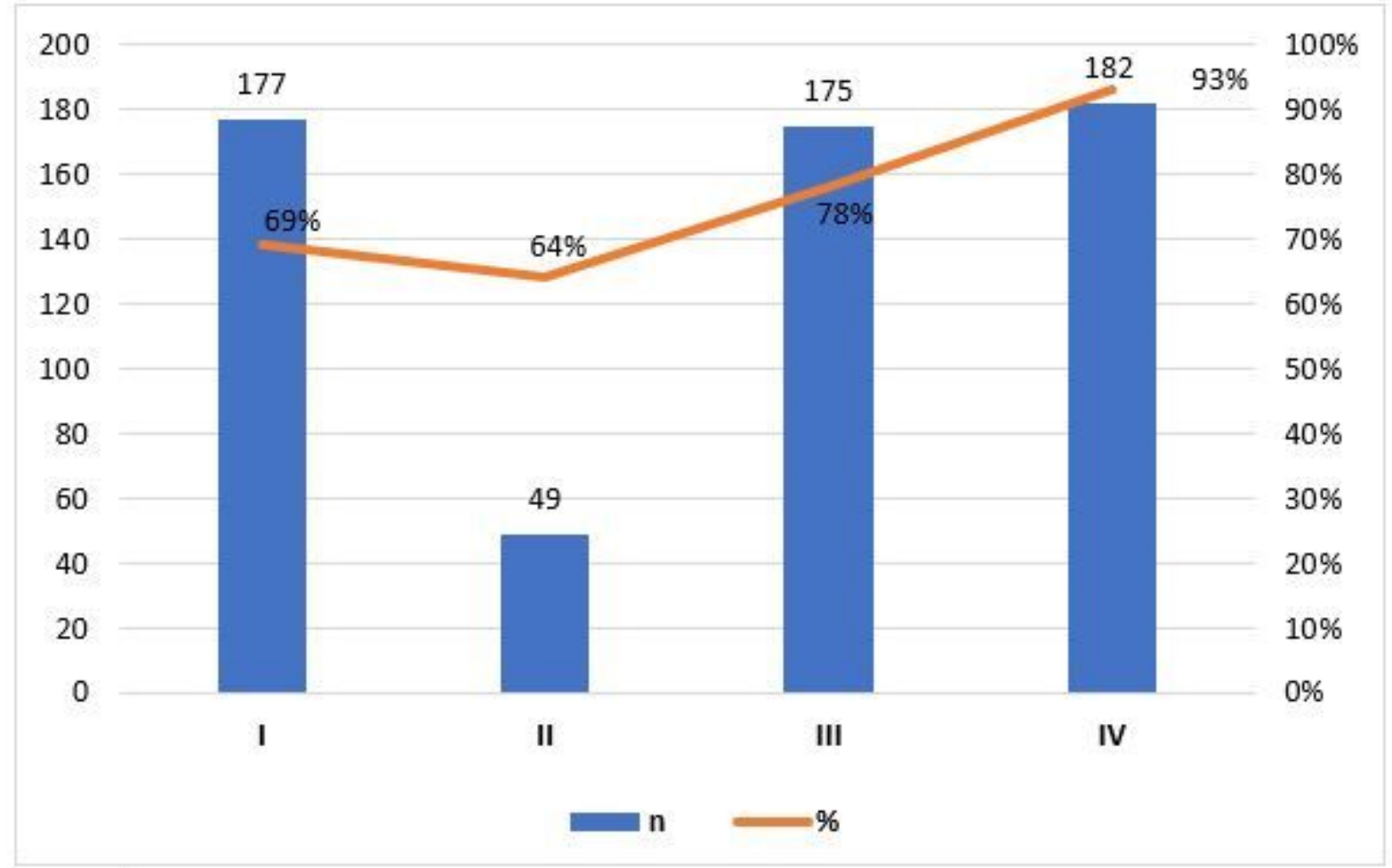

Legend

I - Stage I group, II year of medical students 2015

II- Stage II group, II year and IV years of medical students 2016

III- Stage III group, I year of medical students 2017

IV-Stage III group, II year of medical students 2017

\section{Figure 5}

Results of final OSCE among four groups of participants. 


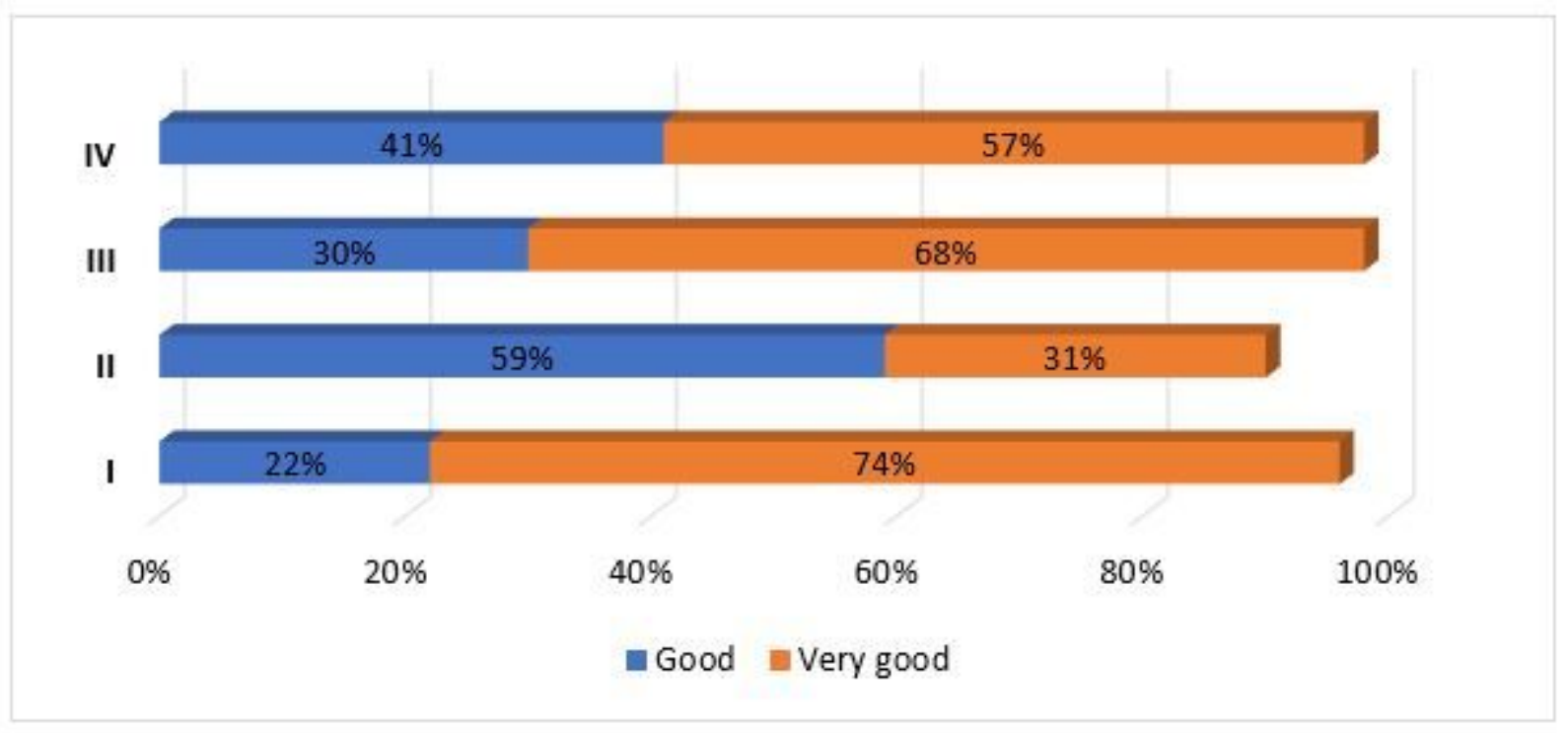

\section{Legend}

I - Stage I group, II year of medical students 2015

II- Stage II group, II year and IV year of medical students 2016

III- Stage III group, I year of medical students 2017

IV- Stage III group, II year of medical students 2017

\section{Figure 6}

Percentage of positive opinions among respondents regarding the BCS course among four groups of respondents from individual stages of research. 


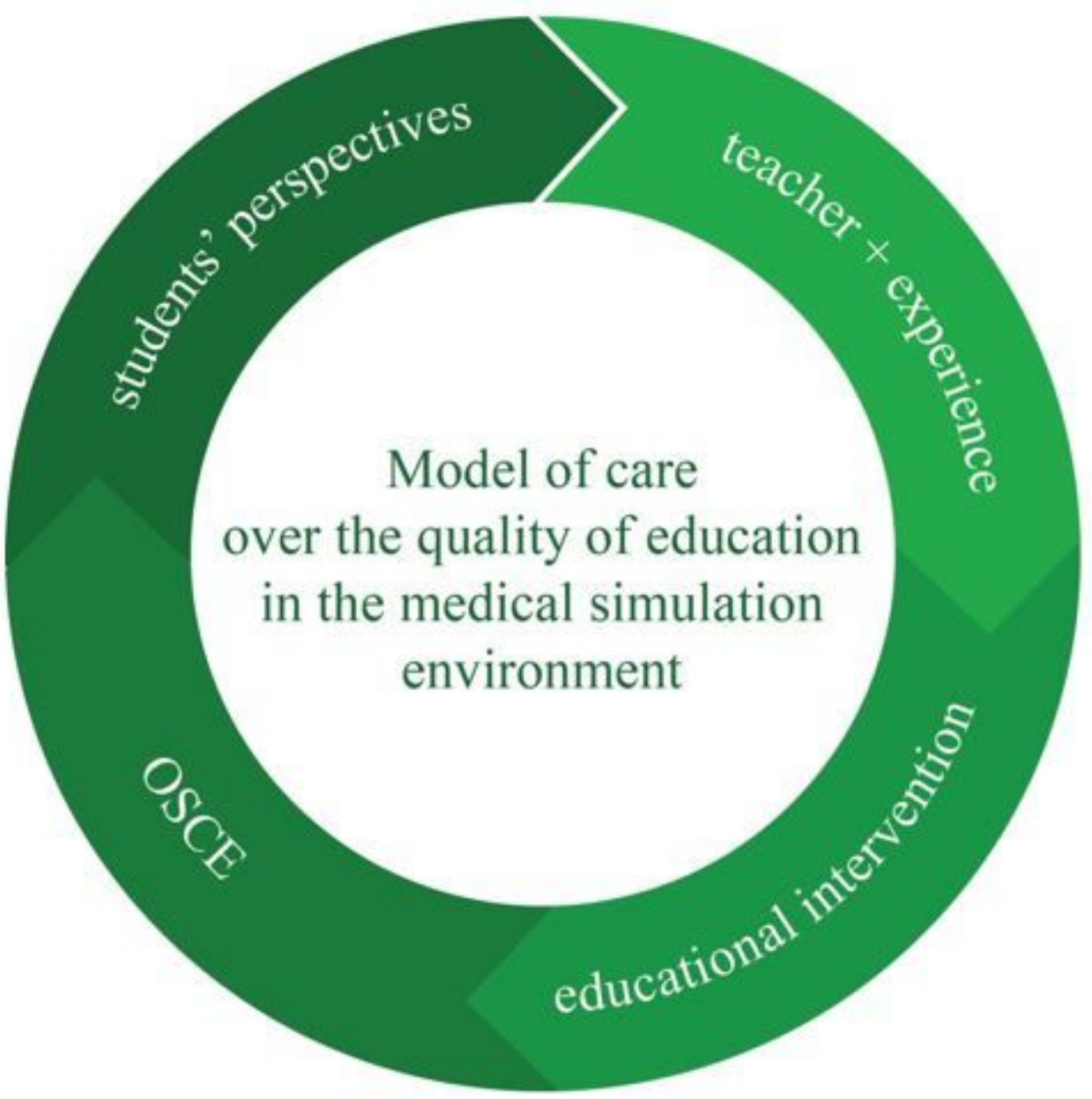

Figure 7

Model of care over the quality of education in the medical simulation environment. 